\title{
Laparoscopic Radical Nephrectomy in Patients with Locally Advanced Renal Cell Carcinoma: Initial Experience
}

\section{Alper Bitkin* and Lokman irkılata}

Samsun Training and Research Hospital, Urology Clinic, University of Health Sciences, Turkey

*Corresponding author: Alper Bitkin, MD, Samsun Training and Research Hospital, Urology Clinic, University of Health Sciences, Ilkadim Samsun/Turkey, Tel: +90-532-5574401, Fax: +90-362-277-88-65

\begin{abstract}
Objective: In this study, we evaluated the results of laparoscopic nephrectomy cases performed in patients with locally advanced renal cell carcinoma.

Methods: Between July 2015 and December 2018, 14 patients underwent laparoscopic nephrectomy for locally advanced renal tumor. The duration of operation, blood loss, duration of hospital stay, perioperative complications and follow-up time were evaluated.

Results: The mean age of the patients was 56.8 (33$78)$. The mean duration of operation was 132.1 (70-190) minutes and the duration of hospital stay was 3.2 (2-5) days. Renal vein thrombus in 3 patients and perirenal fat tissue invasion in 9 patients. In 2 patients, the tumor exceeded the gerota fascia. The mean follow-up period was $18.3(2-41)$ months. Two patients had lung metastasis during follow-up. Two patients died in the $5^{\text {th }}$ and $36^{\text {th }}$ months following the operation.

Conclusion: Nephrectomy improves survival in patients with locally advanced renal tumors. Although the laparoscopic approach has difficulties in these patients, the laparoscopic nephrectomy is a minimally invasive treatment that can be safely performed by experienced surgeons
\end{abstract}

\section{Keywords}

Laparoscopy, Renal cell carcinoma, Locally advanced stage

\section{Abbreviations}

RCC: Renal Cell Carcinoma; LRN: Laparoscopic Radical Nephrectomy; OPN: Open Radical Nephrectomy

\section{Objectives}

Renal cell carcinoma (RCC) accounts for approximately $2-3 \%$ of all malignancies [1]. More than $50 \%$ of renal masses are detected incidentally. Some of these masses do not cause symptoms until late disease stages [2,3]. At diagnosis, $20 \%$ of patients had locally advanced disease and $25 \%$ had metastatic disease [4]. The primary treatment of kidney tumor is surgery. With the advent of minimal invasive techniques, less bleeding, less morbidity, less hospitalization time, decreased analgesic requirement and better cosmetic results were observed in laparoscopic surgery compared to open surgery $[5,6]$. European urology association recommends laparoscopic radical nephrectomy (LRN) to T2 tumors and localized masses that cannot be treated by partial nephrectomy [7]. Although LRN has technical difficulties in patients with locally advanced stage tumors, it has been shown that LRN can be used safely in these patients recently $[8,9]$. In this study, we aimed to share the results of our LRN experience in patients with locally advanced RCC.

\section{Methods}

The data of 14 patients who underwent LRN operation for locally advanced renal tumor (CT3 or CT4 or positive lymph nodes) between July 2015 - December 2018 were retrospectively analyzed. Inclusion criteria; patients with clinical T3 and T4 kidney tumors, patients without metastasis in preoperative imaging, patients without contraindications for laparoscopic surgery. Computerized tomography or magnetic resonance imaging was performed to all patients preoperatively. MR angiography was performed in patients with suspected thrombus in the renal vein and inferior vena cava. Age, body mass index, tumor size, operation time, blood loss, hospital stay, perioperative complications,

Citation: Bitkin A, İrkılata L (2019) Laparoscopic Radical Nephrectomy in Patients with Locally Advanced Renal Cell Carcinoma: Initial Experience. Int Arch Urol Complic 5:053. doi.org/10.23937/2469$5742 / 1510053$

Accepted: February 04, 2019: Published: February 06, 2019

Copyright: (C) 2019 Bitkin A, et al. This is an open-access article distributed under the terms of the Creative Commons Attribution License, which permits unrestricted use, distribution, and reproduction in any medium, provided the original author and source are credited. 
histopathology and follow-up periods were evaluated. Intraoperative and postoperative complications were graded according to Clavien-Dindo classification [10]. All operations were performed transperitoneally. Nasogastric tube and bladder catheter were inserted after general anesthesia. The patients were placed in the lateral decubitus position. Pneumoperitoneum was achieved by transperitoneal Veress needle technique. Three or five ports were used. The first $10-\mathrm{mm}$ port was placed lateral of the umbilicus. A second $10-\mathrm{mm}$ port was placed under $1 / 3$ lateral of the line between the spina iliaca anterior superior and umbilicus under direct vision, third $10-\mathrm{mm}$ port was placed on the midclavicular line 1-2 $\mathrm{cm}$ below the costa borderline. In 4 cases an extra $5 \mathrm{~mm}$ port was placed for liver retraction. In addition, 5-mm port were placed in 4 cases for retraction. Harmonic Scalpe ${ }^{\circledR}$ (Ethicon, UK) or LigaSure ${ }^{\circledR}$ (Covidien Healthcare, MA, USA) were used as the energy source during dissection. The ureter was found after the colon was medicalized, and the ureter was followed and the renal pedicle reached. Arteries and veins were closed and cut using a Hem-o-lok ${ }^{\circledR}$ (Weck-Teleflex, US) clip. In patients with renal vein thrombus, the margins of the tumour thrombus were identified as a prominence in the renal vein. A grasper was used to compress the renal vein distally and milk the thrombus back before applying a hem-o-lok. After that, the ureter was clipped and cut. In 3 cases, adrenalectomy was performed due to the proximity of the mass to the adrenal gland. All surgical operations were performed by a single surgeon with experience in laparoscopy.

\section{Results}

All operations were completed laparoscopically. The mean age of the 14 patients who underwent LRN was 56.8 (33-78). The mean tumor size was 104.7 (72180) $\mathrm{mm}$. The mean operative time was 132.1 (70-190) minutes and the mean estimated blood loss was 142.8

Table 1: Demographic and perioperative data of patients.

\begin{tabular}{|l|l|}
\hline Parameter & Values \\
\hline Number of Patients $(\mathrm{n})$ & 14 \\
\hline Men: Woman & $5: 9$ \\
\hline Mean Age (years) & $56.8(33-78)$ \\
\hline Left/Right & $8 / 6$ \\
\hline Mean Tumor Size (mm) & $104.7(72-180)$ \\
\hline Mean Operation Time (min) & $132.1(70-190)$ \\
\hline Mean Blood Loss (ml) & $142.8(50-300)$ \\
\hline Perioperative Complication (Clavien-Dindo) & \\
\hline Grade 1 & $1(7.2 \%)$ \\
\hline Duration at the hospital (days) & $3.2(2-5)$ \\
\hline Pathology & $10(71.4 \%)$ \\
\hline Clear Cell RCC & $3(21.4 \%)$ \\
\hline Papiller RCC & $1(7.2 \%)$ \\
\hline Chromophore RCC & $12(85.7 \%)$ \\
\hline pT3a & $2(14.3 \%)$ \\
\hline pT4 & $18.3(2-41)$ \\
\hline Mean Follow-up Time (months)
\end{tabular}

(50-300) cc. No blood transfusion was required in any patient. The mean duration of hospital stay was 3.21 (25) days. Only 1 patient had a short-term postoperative fever that responded to medical therapy. Three patients had renal vein thrombus and 9 patients had perirenal adipose tissue involvement. In 2 patients, the tumor exceeded the gerota fascia. The adrenalectomy was performed in 3 patients because the mass was in the upper pole and adjacent to the adrenal gland. Adrenal gland invasion was not observed in 3 patients. The surgical margin of all patients was negative. The mean follow-up period was 18.3 (2-41) months. Metastasis was detected in 2 patients (lung). Two patients died in the $5^{\text {th }}$ and $36^{\text {th }}$ months following the operation. Demographic and perioperative data of the patients are shown in Table 1.

\section{Discussion}

LRN was first applied by Clayman, et al. In 1991 [11]. Since then, there has been an increase in the number of laparoscopic cases with improvements in minimally invasive surgery and increased surgical experience. Approximately $61 \%$ of radical nephrectomy is now performed laparoscopically [12]. Although LRN has a definite role in the localized RCC stage in the surgery of kidney tumors, the number of studies related to its reliability in the locally advanced stage is limited [13]. LRN in localized kidney tumors has been shown to be more advantageous in terms of blood loss, need for analgesia, length of hospital stay and healing process compared to open surgery and has similar oncologic results $[6,14]$. Due to these advantages of laparoscopic surgery, it was thought that laparoscopic nephrectomy could be performed in patients with renal tumors in the locally advanced stage. Bragaryac, et al. performed laparoscopic/robotic radical nephrectomy in 67 patients with pT3 and pT4 RCC and open radical nephrectomy (ORN) in 105 patients. In the laparoscopic/robotic group, the mean operative time was 294 minutes, the mean estimated blood loss was $277 \mathrm{cc}$ and the hospital stay was 3.5 days. They concluded that hospital stay and blood loss were more advantageous than open surgery [9]. Nayak, et al. shared the results of 176 T3 RCC patients who underwent laparoscopic surgery. They reported the mean tumor size of $7 \mathrm{~cm}$, the mean operation time of $124 \mathrm{~min}$, and the mean estimated blood loss of $150 \mathrm{cc}$ [15]. The mean operative time of the patients who underwent LRN for 94 locally advanced RCC was 150 minutes, the mean estimated blood loss was $100 \mathrm{cc}$, the conversion from laparoscopic to open surgery was $6.4 \%$, and the hospital stay was 5 days [16]. Laird, et al. matched comprasion of 25 LRN and 25 ORN for T3 RCC patients. In the LRN group, the tumor size was $8.7 \mathrm{~cm}$, the mean operation time was $135 \mathrm{~min}$, the mean estimated blood loss was $100 \mathrm{cc}$, and the hospital stay was 4 days. Perioperative results were better in the LRN group [8]. In our cases, the mean tumor size was measured as $10.4 \mathrm{~cm}$. The mean operation time 
was $132.1 \mathrm{~min}$, and the mean estimated blood loss was $142.8 \mathrm{cc}$. The mean duration of hospital stay was 18.3 months. The perioperative results showed that LRN can be safely applied in the locally advenced RCC.

One of the most important steps of oncologic surgery is how it affects oncological outcomes. In a study in which the patients with locally advanced RCC who underwent ORD and LRN/robotic RN were followed up for an average of 32.8 months, there was no significant difference in overall survival $(p=0.8)$ between the two groups [9]. Nayak, et al. followed 176 patients with T3 RCC who underwent LRN for a mean of 22.6 months. 43 patients had distant metastasis and 3 patients had local recurrence. 6 patients died due to kidney cancer [15]. In another study involving 94 patients who underwent LRN for locally advanced disease, the follow-up period was 24.8 months. 12 patients had distant metastasis and 5 patients had local recurrence. In a study comparing patients who underwent LRN and ORN in patients with T3 $\mathrm{RCC}$, the mean follow-up period was 54.6 months in the LRN group and 57.6 months in the ORN group. Overall survival, cancer specific survival and progression free survival were not different between the two groups [8]. In our study, the mean follow-up period was 18.3 (2-41) months. Two patients had lung metastasis during follow-up. No local recurrence was observed. Two patients died following RCC operation in the $5^{\text {th }}$ and $36^{\text {th }}$ months.

Locally advanced renal tumors are quite difficult for laparoscopic surgery because of the complications that can be caused by thrombus in the renal vein and vena cava, and bleeding caused by neovascularization of large tumors. Therefore, case selection and the experience of the surgeon are very important. Our cases were performed by a single surgeon experienced in laparoscopy.

\section{Limitations}

There are some limitations to this study. First, the number of cases is small and the absence of patients with vena cava thrombus in the local advanced stage RCC may have affected the perioperative results. Second, overall survival and cancer-specific survival were not evaluated due to the low number of cases and short follow-up period.

\section{Conclusion}

In patients with locally advanced RCC, LRN appears to be a safe and effective minimally invasive treatment option in selected cases and when performed by experienced surgeons. To confirm our results, prospective randomized studies with more number of patients and longer follow-up periods are required.

\section{Conflict of Interest}

The authors report no conflict of interests. The authors alone are responsible for the content and writing of the manuscript.

\section{References}

1. (2001) European Network of Cancer Registries: Eurocim Version 4.0. Lyon, France.

2. Novara G, Ficarra V, Antonelli A, Artibani W, Bertini R, et al. (2010) Validation of the 2009 TNM version in a large multi-institutional cohort of patients treated for renal cell carcinoma: Are further improvements needed? Eur Urol 58: 588-595.

3. Waalkes S, Becker F, Schrader AJ, Janssen M, Wegener $G$, et al. (2011) Is there a need to further subclassify pT2 renal cell cancers as implemented by the revised $7^{\text {th }}$ TNM version? Eur Urol 59: 258-263.

4. Flanigan RC, Campbell SC, Clark JI, Picken MM (2003) Metastatic renal cell carcinoma. Current Treatment Options in Oncology 4: 385-390.

5. Shuford MD, McDougall EM, Chang SS, LaFleur BJ, Smith JA Jr, et al. (2004) Complications of contemporary radical nephrectomy: Comparison of open vs. laparoscopic approach. Urol Oncol 22: 121-126.

6. Hemal AK, Kumar A, Kumar R, Wadhwa P, Seth A, et al. (2007) Laparoscopic versus open radical nephrectomy for large renal tumors: A long-term prospective comparison. $J$ Urol 177: 862-866.

7. B Ljungberg, L Albiges, $K$ Bensalah, A Bex, RH Giles, et al. (2017) EAU Guidelines on renal cell carcinoma. European Association of Urology.

8. Laird A, Choy KC, Delaney H, Cutress ML, O'Connor KM, et al. (2015) Matched pair analysis of laparoscopic versus open radical nephrectomy for the treatment of T3 renal cell carcinoma. World J Urol 33: 25-32.

9. Bragayrac LA, Abbotoy D, Attwood K, Darwiche F, Hoffmeyer J, et al. (2016) Outcomes of minimal invasive vs. open radical nephrectomy for the treatment of locally advanced renal-cell carcinoma. J Endourol 30: 871-876.

10. Clavien PA, Barkun J, de Oliveira ML, Vauthey JN, Dindo D, et al. (2009) The Clavien-Dindo classification of surgical complications: Five-year experience. Ann Surg 250: 187196.

11. Clayman RV, Kavoussi LR, Soper NJ, Dierks SM, Meretyk S, et al. (1991) Laparoscopic nephrectomy: Initial case report. J Urol 146: 278-282.

12. Liu JJ, Leppert JT, Maxwell BG, Panousis P, Chung BI (2014) Trends and perioperative outcomes for laparoscopic and robotic nephrectomy using the National Surgical Quality Improvement Program (NSQIP) database. Urol Oncol 32: 473-479.

13. Bolton EM, Hennessy D, Lonergan PE, Darcy FT, Manecksha RP, et al. (2018) Evaluating the perioperative safety of laparoscopic radical nephrectomy for large, nonmetastatic renal tumours: A comparative analysis of T1-T2 with T3a tumours. Ir J Med Sci 187: 313-318.

14. Dunn MD, Portis AJ, Shalhav AL, Elbahnasy AM, Heidorn C, et al. (2000) Laparoscopic versus open radical nephrectomy: A 9-year experience. J Urol 164: 1153-1159.

15. Nayak JG, Patel P, Bjazevic J, Liu Z, Saarela O, et al. (2015) Clinical outcomes following laparoscopic management of pT3 renal masses: A large, multi-institutional cohort. Can Urol Assoc J 9: 397-402.

16. Stewart GD, Ang WJ, Laird A, Tolley DA, Riddick AC, et al. (2012) The operative safety and oncological outcomes of laparoscopic nephrectomy for T3 renal cell cancer. BJU Int 110: 884-890. 